\title{
Role of Serine140 in the mode of action of Mycobacterium tuberculosis $\beta$-ketoacyl-ACP Reductase (MabA)
}

Leonardo A Rosado ${ }^{1,2,4}$, Rafael Andrade Caceres ${ }^{2,3}$, Walter Filgueira de Azevedo $\mathrm{Jr}^{3,4}$, Luiz A Basso $0^{1,4^{*}}$ and Diógenes S Santos ${ }^{1,4^{*}}$

\begin{abstract}
Background: Tuberculosis (TB) still remains one of the most deadly infectious diseases in the world. Mycobacterium tuberculosis $\beta$-ketoacyl-ACP Reductase (MabA) is a member of the fatty acid elongation system type II, providing precursors of mycolic acids that are essential to the bacterial cell growth and survival. MabA has been shown to be essential for M. tuberculosis survival and to play a role in intracellular signal transduction of bacilli.

Findings: Here we describe site-directed mutagenesis, recombinant protein expression and purification, steady-state kinetics, fluorescence spectroscopy, and molecular modeling for S140T and S140A mutant MabA enzymes. No enzyme activity could be detected for S140T and S140A. Although the S140T protein showed impaired NADPH binding, the S140A mutant could bind to NADPH. Computational predictions for NADPH binding affinity to WT, S140T and S140A MabA proteins were consistent with fluorescence spectroscopy data.

Conclusions: The results suggest that the main role of the S140 side chain of MabA is in catalysis. The S140 side chain appears to also play an indirect role in NADPH binding. Interestingly, NADPH titrations curves shifted from sigmoidal for WT to hyperbolic for S140A, suggesting that the S140 residue may play a role in displacing the pre-existing equilibrium between two forms of MabA in solution. The results here reported provide a better understanding of the mode of action of MabA that should be useful to guide the rational (function-based) design of inhibitors of MabA enzyme activity which, hopefully, could be used as lead compounds with anti-TB action.
\end{abstract}

Keywords: Mycobacterium tuberculosis, $\beta$-Ketoacyl-ACP Reductase, MabA, Site-directed mutagenesis, Enzyme activity, Fluorescence spectroscopy, Molecular modeling

\section{Findings}

\section{Background}

Tuberculosis (TB) remains the leading cause of mortality due to a bacterial pathogen, Mycobacterium tuberculosis [1]. In 2008, there were an estimated 8.9-9.9 million incident cases of TB, killing two million people annually [2]. In addition, there were an estimated 0.5 million cases of

\footnotetext{
* Correspondence: luiz.basso@pucrs.br; diogenes@pucrs.br

${ }^{1}$ Centro de Pesquisas em Biologia Molecular e Funcional (CPBMF), Instituto Nacional de Ciência e Tecnologia em Tuberculose (INCT-TB), Pontifícia Universidade Católica do Rio Grande do Sul (PUCRS), Av. Ipiranga 6681, Porto Alegre, RS 90619-900, Brazil

${ }^{4}$ Programa de Pós-Graduação em Biologia Celular e Molecular, PUCRS, Av. Ipiranga 6681 - Tecnopuc - Prédio 92A, ZIP CODE 90619-900, Porto Alegre, RS, Brazil

Full list of author information is available at the end of the article
}

multi-drug resistant TB (MDR-TB), which is defined as strains resistant to, at least, isoniazid and rifampicin [2]. The emergence of extensively drug-resistant (XDR-TB) TB cases, defined as cases in persons with TB whose isolates are MDR that are also resistant to a fluoroquinolone and, at least, one second-line injectable agent (amikacin, kanamycin and/or capreomycin) [2,3], its widespread distribution [4], and unprecedented fatality rate [5], raise the prospect of virtually incurable and deadly TB worldwide. Recently, a total new strain was identified as resistant to all first and second line of antiTB drugs tested [6,7]. There is thus is an urgent need for the development of new antimycobacterial agents.

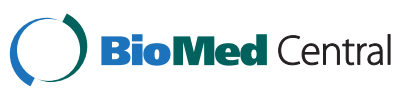


The type II fatty acid biosynthesis system (FAS-II) is present in bacteria, plants and organisms of the phylum Apicomplexa, but generally considered to be absent from mammals. M. tuberculosis mabA(fabG1)-encoded $\beta$-ketoacyl-ACP Reductase (MabA) is a member of FAS-II system, which elongates acyl fatty acid precursors yielding the long carbon chain of the meromycolate branch of mycolic acids, the hallmark of mycobacteria [8]. It has been shown that MabA is essential for M. tuberculosis survival [9]. Post-translational phosphorylation of MabA by Ser/Thr protein kinase activity has been shown to negatively regulate mycolic acid biosynthesis [10]. The dehydratases of M. tuberculosis FAS-II (HadAB and HadBC) and methyltransferases have recently been shown to be part of a mycolic acid biosynthesis interactome, which is involved in coordinating elongation and chemical modification of mycolic acids [11]. For enzyme-targeted drug programs, however, mechanistic analysis should always be a top priority because effective enzyme inhibitors take advantage of enzyme chemistry to achieve inhibition [12]. As MabA represents a possible target for anti-tubercular agent development, the work here described was undertaken.

MabA belongs to the family of short-chain dehydrogenases/Reductase (SDR) [13], displaying a preference for NADPH over NADH, and higher specificity for long $\beta$-ketoacyl chains [14]. Crystal structure of MabA revealed a conserved Rossmann fold and the Ser-Tyr-Lys catalytic triad conserved among SDR members [15]. The conserved catalytic triad of MabA corresponds to the following signature: $\mathrm{S} 140(\mathrm{X})_{12} \mathrm{Y} 153(\mathrm{X})_{3} \mathrm{~K} 157$. The catalytic triads of SDR proteins catalyze abstraction of the proton from the substrate grouping $\mathrm{H}-\mathrm{C}-\mathrm{O}-\mathrm{H}$, although they also catalyze reduction of $\mathrm{C}=\mathrm{C}$ and $\mathrm{C}=\mathrm{N}$ double bonds, and mediate dehydratase, as well as sulfotransferase, isomerase, and decarboxylation reactions [16]. The dependence of MabA initial velocity on $\mathrm{pH}$ values has identified a single enzyme group with a $\mathrm{p} K_{\mathrm{a}}$ value of 9.6 that abolishes activity upon deprotonation, which has been proposed to likely be either Tyr or Lys component of the Ser-Tyr-Lys triad [17]. However, it has been suggested that the Ser138 of the catalytic triad plays a catalytic role in Drosophila alcohol dehydrogenase, an SDR protein [18]. On the other hand, the Ser residues of the catalytic triad of SDR proteins have been suggested to play a minor role, if any, in catalysis [19]. Analysis of MabA crystal structure in the apo form showed a $90^{\circ}$ rotation of Tyr153 phenol ring that was proposed to be induced by the hydroxyl group of "catalytic" Ser140 [15]. In this particular arrangement, S140 is placed into the position occupied by the nicotinamide ribose of NADP in the holo-form [15]. However, there has been no report on the role, if any, of S140 in the mode of binding and/or catalysis of MabA.

\section{Side-directed mutagenesis, recombinant protein expression and purification}

To evaluate the role of S140 residue in MabA, S140T and S140A mutants were produced by site-directed mutagenesis. The singly mutated genes corresponding to S140T and S140A were generated using the Quick Change SiteDirected Mutagenesis Kit (Stratagene) according to the manufacturer's instructions and pET23a(+):mabA as the template. The mutant genes were sequenced in their entirety to ensure that no unexpected mutations occurred. The recombinant plasmid was transformed into Escherichia coli BL21(DE3) cells (Novagen) and grown in LuriaBertani medium $50 \mathrm{~g} \mathrm{~mL}^{-1}$ carbenicillin, at $37^{\circ} \mathrm{C}$ to a value of 0.4 for absorbance at $600 \mathrm{~nm}$, and induced by the addition of isopropyl-1-thio- $\beta$-D-galactopyranoside (IPTG) to a final concentration of $0.1 \mathrm{mM}$. Cells were allowed to grow for an additional $4 \mathrm{~h}$ and harvested by centrifugation at 20,800 $\mathrm{g}$ for $30 \mathrm{~min}$. Soluble S140T and S140A mutant MabA proteins were purified to homogeneity as described elsewhere [17,20]. Samples of the purification steps were analyzed by SDS-PAGE [21] and protein content by the Bradford's method [22].

\section{Steady-state kinetics measurements}

Activity assays of homogeneous S140T and S140A mutant enzymes were carried out under steady-state conditions at $25^{\circ} \mathrm{C}$ and $100 \mathrm{mM}$ HEPES, $\mathrm{pH} 7.0$, measuring decrease in absorbance at $370 \mathrm{~nm}\left(\epsilon=2,320 \mathrm{M}^{-1} \mathrm{~cm}^{-1}\right)$ upon oxidation of $\mathrm{NADPH}(1.5-6 \mathrm{mM})$ in the presence of acetoacetyl-CoA (AcAcCoA: $2-8 \mathrm{mM}$ ). These concentrations are well above the $K_{\mathrm{M}}$ values for NADPH $(26 \mu \mathrm{M})$ and AcAcCoA $(165 \mu \mathrm{M})$ [17]. In addition, increasing mutant enzyme concentrations $(0.48 \mu \mathrm{M} \leq \mathrm{S} 140 \mathrm{~T} \leq 3.45 \mu \mathrm{M}$; $0.36 \mu \mathrm{M} \leq \mathrm{S} 140 \mathrm{~A} \leq 2.6 \mu \mathrm{M})$ were tested to try to detect $\beta$-ketoacyl Reductase activity, if any. The S140T and S140A mutants had no detectable activity under these experimental conditions.

\section{Fluorescence spectroscopy}

To ascertain whether these mutations affected catalysis or substrate binding, enhancement in nucleotide fluorescence upon NADPH binding to MabA was employed to evaluate the overall dissociation constant for binary complex formation at equilibrium $\left(K_{\mathrm{d}}\right)$, as previously described [20]. Fluorescence titration of NADPH binding to either S140T or S140A mutants at equilibrium was carried out at $25^{\circ} \mathrm{C}$ by making micro liter additions of $10 \mathrm{mM} \mathrm{NADPH}$ to $2 \mathrm{~mL}$ of $4 \mu \mathrm{M}$ mutant protein in $100 \mathrm{mM}$ Hepes, $\mathrm{pH} 7.0$, keeping the dilution to a maximum of $0.75 \%$. Nucleotide fluorescence excitation and emission wavelengths were, respectively, 360 and $520 \mathrm{~nm}$ (maximum $\lambda_{\mathrm{em}}=460 \mathrm{~nm}$ ). The slits for excitation and emission were, respectively, 1.5 and $5 \mathrm{~nm}$. Control measurements were performed under the same 
conditions, except that no enzyme was added, and these values were subtracted from those obtained in the presence of the enzyme. This control was also employed to determine the maximum NADPH concentration to be utilized with no significant inner filter effect. Data were plotted as $\Delta$ relative fluorescence versus NADPH concentration $(4.99-123.45 \mu \mathrm{M}$ for S140T, and $4.99-39.83 \mu \mathrm{M}$ for S140A). Larger values for NADPH concentrations could not be used due to significant inner filter effect. No binding of NADPH to S140T mutant protein could be detected (Figure 1 - inset), indicating a $K_{\mathrm{d}}$ value larger than $123 \mu \mathrm{M}$. This result suggests that the S140T change resulted in impaired substrate binding and, consequently, catalysis. On the other hand, the S140A mutant protein could bind NADPH (Figure 1), and fitting the data to a hyperbolic function yielded an overall dissociation constant $\left(K_{\mathrm{d}}\right)$ value of $26( \pm 9) \mu \mathrm{M}$. This result suggests that S140 residue plays a role in catalysis. This result also demonstrates that the loss of enzyme activity of mutant protein is not due to gross structural changes.

\section{Molecular modeling}

Several attempts to obtain crystals for S140T and S140A MabA proteins were unsuccessful in our hands. Accordingly, to try to interpret the steady-state kinetics measurements and fluorescence spectroscopy results at a molecular level, bioinformatics tools were used. Homology modeling is based on the assumption that tertiary structures of two proteins will be similar if their sequences were related, and it is the approach most likely to give accurate results [23]. The homology models for S140T and S140A mutants in complex with NADPH were obtained using the coordinates of WT InhA as template (PDB ID 1UZN) and the restrained-based modeling implemented in the Modeler 9v5 program [24]. A total of 1000 models were generated and the final models were selected based on the objective function obtained from Modeler 9v5 [24]. The selected models were submitted to energy minimization in water, employing the GROMACS [25] package using Gromos 96.1 (53A6) force field [26] to make the analysis between protein and NADPH more realistic. Each structure was placed in the center of a truncated cubic box filled with Extended Simple Point Charge (SPC/E) water molecules [27], and the protein solvated by a layer of water molecules of at least $10 \AA$ in all directions in both systems. The binary complex and water molecules were subjected to 1500 steps of energy minimization by conjugate gradient to remove close van der Waals contacts, and the overall stereochemical quality of the final models was assessed by the program PROCHECK [28]. Analysis of the Ramachandran diagram $\Phi-\psi$ plots indicated that all models had over $95 \%$ of the residues in the most favorable regions.

The specificity and affinity between enzyme and its substrate depend on directional hydrogen bonds and ionic interactions, as well as on shape complementarity of the contact surfaces of both partners [29,30]. Analysis of the hydrogen bonds between either WT, S140T, or S140A MabA protein and NADPH (Table 1) reveals, respectively, sixteen (Figure 2), twelve (Figure 3), and ten (Figure 4) intermolecular hydrogen bonds. The WT MabA, S140A and S140T models are shown superimposed in Figure 5. The hydrogen bonds were calculated by LIGPLOT program [31] with a $3.5 \AA$ cutoff. The XSCORE [32], LigScore [33], and Drugstore [34]

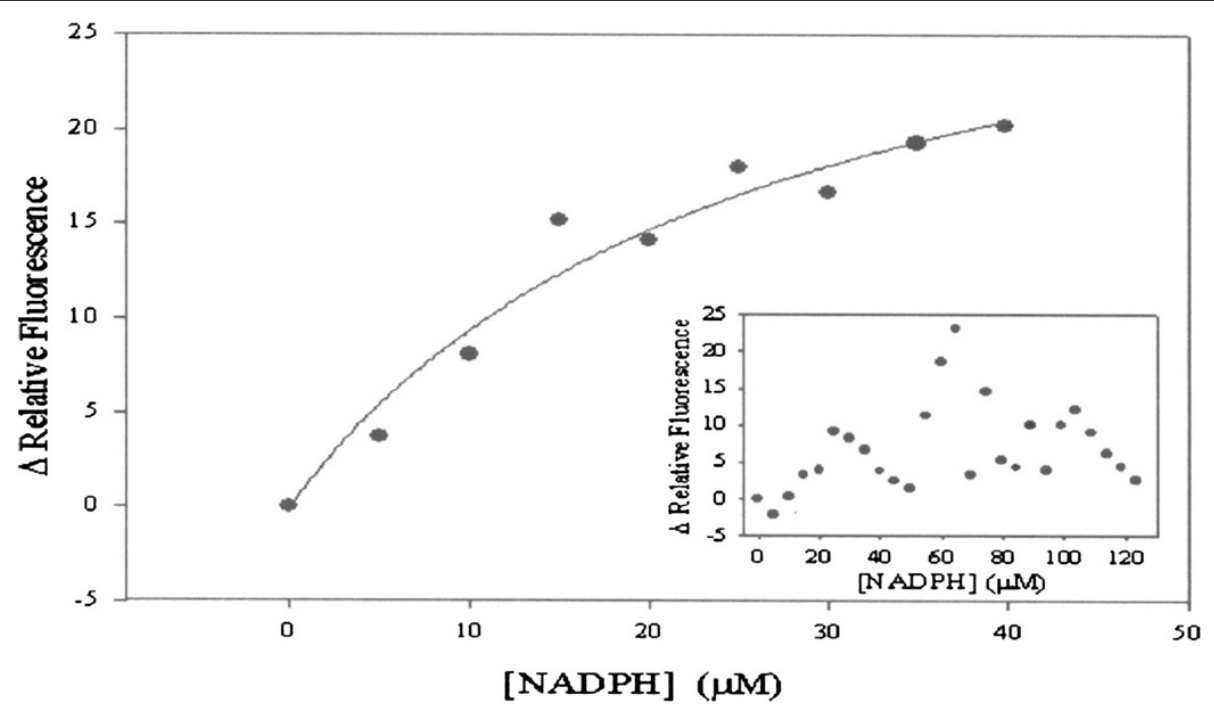

Figure 1 Fluorescence spectroscopy of equilibrium binding of NADPH to MabA mutant proteins. Dependence of the enhancement in nucleotide fluorescence upon NADPH binding to S140A mutant. Inset: NADPH titration of S140T mutant protein. 
Table 1 Hydrogen bonds between amino acid residues and NADPH for WT, S140A and S140T MabA proteins

\begin{tabular}{|c|c|c|c|c|}
\hline \multirow[b]{2}{*}{ Protein } & \multicolumn{3}{|c|}{ Hydrogen bond } & \multirow{2}{*}{$\frac{\text { Hydrophobic contac }}{\text { Residues }}$} \\
\hline & Residues & Atoms & Distance $(\AA \AA)$ & \\
\hline \multirow[t]{16}{*}{ MtMabAWT } & Gly22 & $\mathrm{O} \rightarrow \mathrm{O} 3 \mathrm{~B}$ & 2.9 & Pro183 \\
\hline & Asn24 & $\mathrm{OD} 1 \rightarrow \mathrm{O} 3 \mathrm{~B}$ & 2.9 & Val217 \\
\hline & Ile27 & $\mathrm{N} \rightarrow \mathrm{O} 2 \mathrm{~N}$ & 2.9 & \\
\hline & & $\mathrm{ND} 2 \rightarrow \mathrm{O} 2 \mathrm{X}$ & 3.0 & \\
\hline & Arg47 & $\mathrm{NH} 2 \rightarrow \mathrm{O} 1 \mathrm{X}$ & 3.4 & \\
\hline & & $\mathrm{NE} \rightarrow \mathrm{O} 1 \mathrm{X}$ & 2.90 & \\
\hline & & $\mathrm{N} \rightarrow \mathrm{O} 2 \mathrm{X}$ & 3.1 & \\
\hline & Asp61 & $\mathrm{OD} 1 \rightarrow \mathrm{N} 6 \mathrm{~A}$ & 3.2 & \\
\hline & Val62 & $\mathrm{N} \rightarrow \mathrm{N} 1 \mathrm{~A}$ & 3.0 & \\
\hline & Gly90 & $\mathrm{N} \rightarrow \mathrm{O} 4 \mathrm{~B}$ & 3.2 & \\
\hline & Asn88 & $\mathrm{O} \rightarrow \mathrm{O} 3 \mathrm{D}$ & 3.2 & \\
\hline & Ile138 & $\mathrm{O} \rightarrow \mathrm{O} 3 \mathrm{D}$ & 3.1 & \\
\hline & Gly139 & $\mathrm{N} \rightarrow \mathrm{O} 2 \mathrm{D}$ & 3.3 & \\
\hline & Tyr153 & $\mathrm{OH} \rightarrow \mathrm{O} 2 \mathrm{D}$ & 3.0 & \\
\hline & Ile186 & $\mathrm{N} \rightarrow \mathrm{O} 7 \mathrm{~N}$ & 3.0 & \\
\hline & Lys157 & $\mathrm{NZ} \rightarrow \mathrm{O} 3 \mathrm{D}$ & 3.1 & \\
\hline \multirow[t]{10}{*}{ MtMabAS140A } & Gly22 & $\mathrm{O} \rightarrow \mathrm{O} 3 \mathrm{~B}$ & 2.9 & Asp61 \\
\hline & Asn24 & $\mathrm{OD} 1 \rightarrow \mathrm{O} 3 \mathrm{~B}$ & 2.9 & Pro183 \\
\hline & Ile27 & $\mathrm{N} \rightarrow \mathrm{O} 2 \mathrm{~N}$ & 3.0 & Val217 \\
\hline & Val62 & $\mathrm{N} \rightarrow \mathrm{N} 1 \mathrm{~A}$ & 2.9 & \\
\hline & Asn88 & $\mathrm{O} \rightarrow \mathrm{O} 3 \mathrm{D}$ & 3.0 & \\
\hline & Gly90 & $\mathrm{N} \rightarrow \mathrm{O} 4 \mathrm{~B}$ & 3.1 & \\
\hline & Ile138 & $\mathrm{O} \rightarrow \mathrm{O} 3 \mathrm{D}$ & 3.2 & \\
\hline & Gly139 & $\mathrm{N} \rightarrow \mathrm{O} 2 \mathrm{D}$ & 3.4 & \\
\hline & Tyr153 & $\mathrm{OH} \rightarrow \mathrm{O} 2 \mathrm{D}$ & 3.2 & \\
\hline & Ile186 & $\mathrm{N} \rightarrow \mathrm{O} 7 \mathrm{~N}$ & 2.9 & \\
\hline \multirow[t]{12}{*}{ MtMabAS140T } & Gly22 & $\mathrm{O} \rightarrow \mathrm{O} 3 \mathrm{~B}$ & 3.0 & Asp61 \\
\hline & Asn24 & $\mathrm{OD} 1 \rightarrow \mathrm{O} 3 \mathrm{~B}$ & 3.0 & $\operatorname{Arg} 25$ \\
\hline & Ile27 & $\mathrm{N} \rightarrow \mathrm{O} 2 \mathrm{~N}$ & 3.1 & Ala89 \\
\hline & Val62 & $\mathrm{N} \rightarrow \mathrm{N} 1 \mathrm{~A}$ & 2.8 & Pro183 \\
\hline & Asn88 & $\mathrm{O} \rightarrow \mathrm{O} 3 \mathrm{D}$ & 3.0 & Val217 \\
\hline & & $\mathrm{OD} 1 \rightarrow \mathrm{O} 3$ & 3.3 & \\
\hline & Gly90 & $\mathrm{N} \rightarrow \mathrm{O} 4 \mathrm{~B}$ & 3.1 & \\
\hline & Ile138 & $\mathrm{O} \rightarrow \mathrm{O} 3 \mathrm{D}$ & 3.4 & \\
\hline & Gly139 & $\mathrm{O} \rightarrow \mathrm{O} 2 \mathrm{D}$ & 3.4 & \\
\hline & Tyr153 & $\mathrm{OH} \rightarrow \mathrm{O} 2 \mathrm{D}$ & 3.0 & \\
\hline & Ile186 & $\mathrm{N} \rightarrow \mathrm{O} 7 \mathrm{~N}$ & 2.9 & \\
\hline & Tyr188 & $\mathrm{OG} 1 \rightarrow \mathrm{N} 7 \mathrm{~N}$ & 2.8 & \\
\hline
\end{tabular}

programs were employed to evaluate the binding affinity of NADPH for WT and mutant MabA proteins. The computational predictions for $\mathrm{p} K_{\mathrm{d}}\left(-\log K_{\mathrm{d}}\right)$ values for WT MabA, S140A and S140T mutants for NADPH binary complex formation are given in Table 2.

\section{Discussion}

Although a component of the Ser-Tyr-Lys catalytic triad has been proposed to play a role in either catalysis and/or binding based on the dependence of WT MabA enzyme activity on various $\mathrm{pH}$ values [17], there has been no 


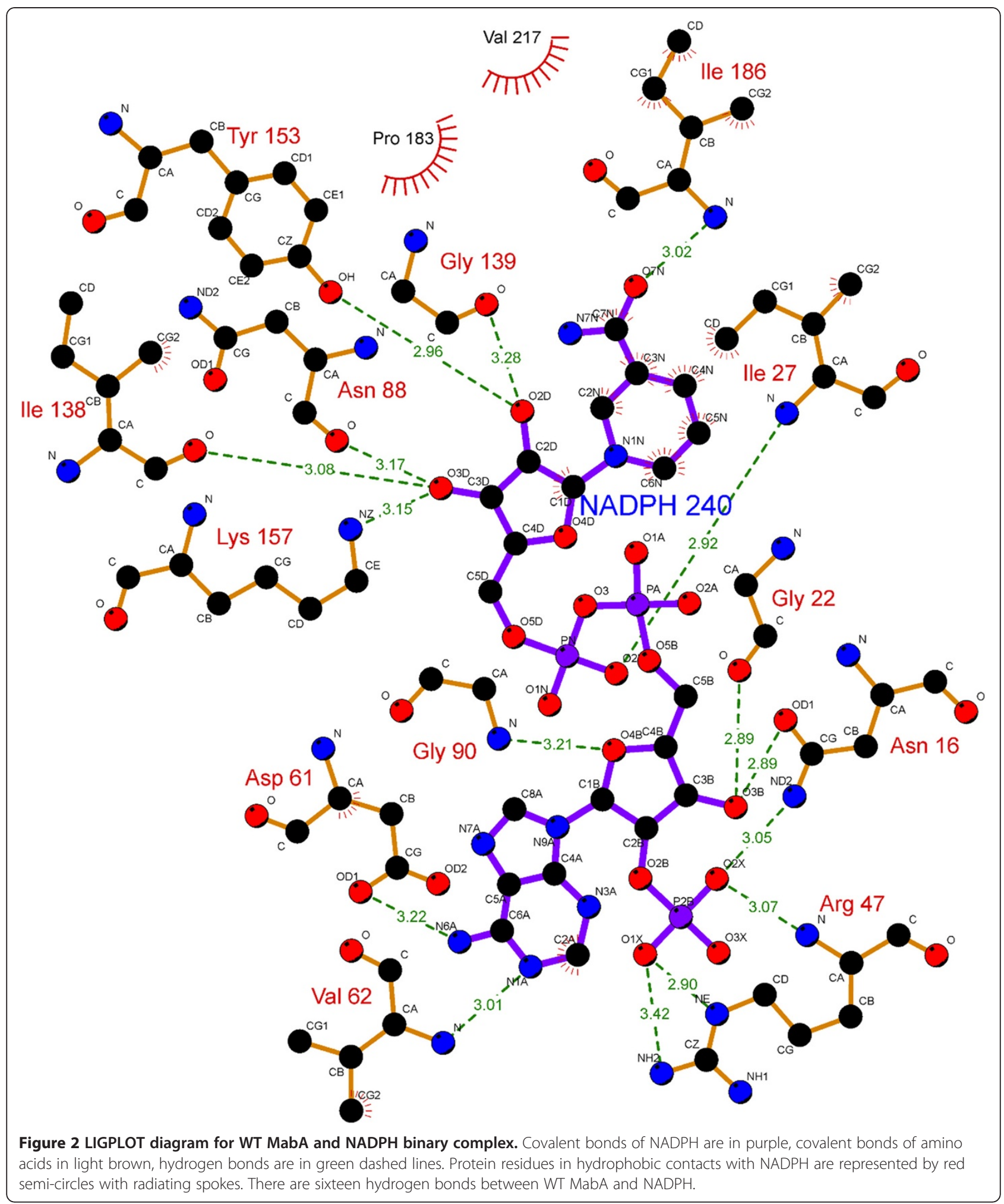

report on site-directed mutagenesis to unambiguously assign any role to the S140 residue of MabA. Pre-steady state kinetics of WT MabA: NADPH binary complex formation has shown that there are two forms of free WT
MabA in equilibrium in solution with different affinity for NADPH [20], consistent with the symmetry model [35]. Equilibrium NADPH binding to WT MabA was shown to display strong positive homotropic cooperativity, with 


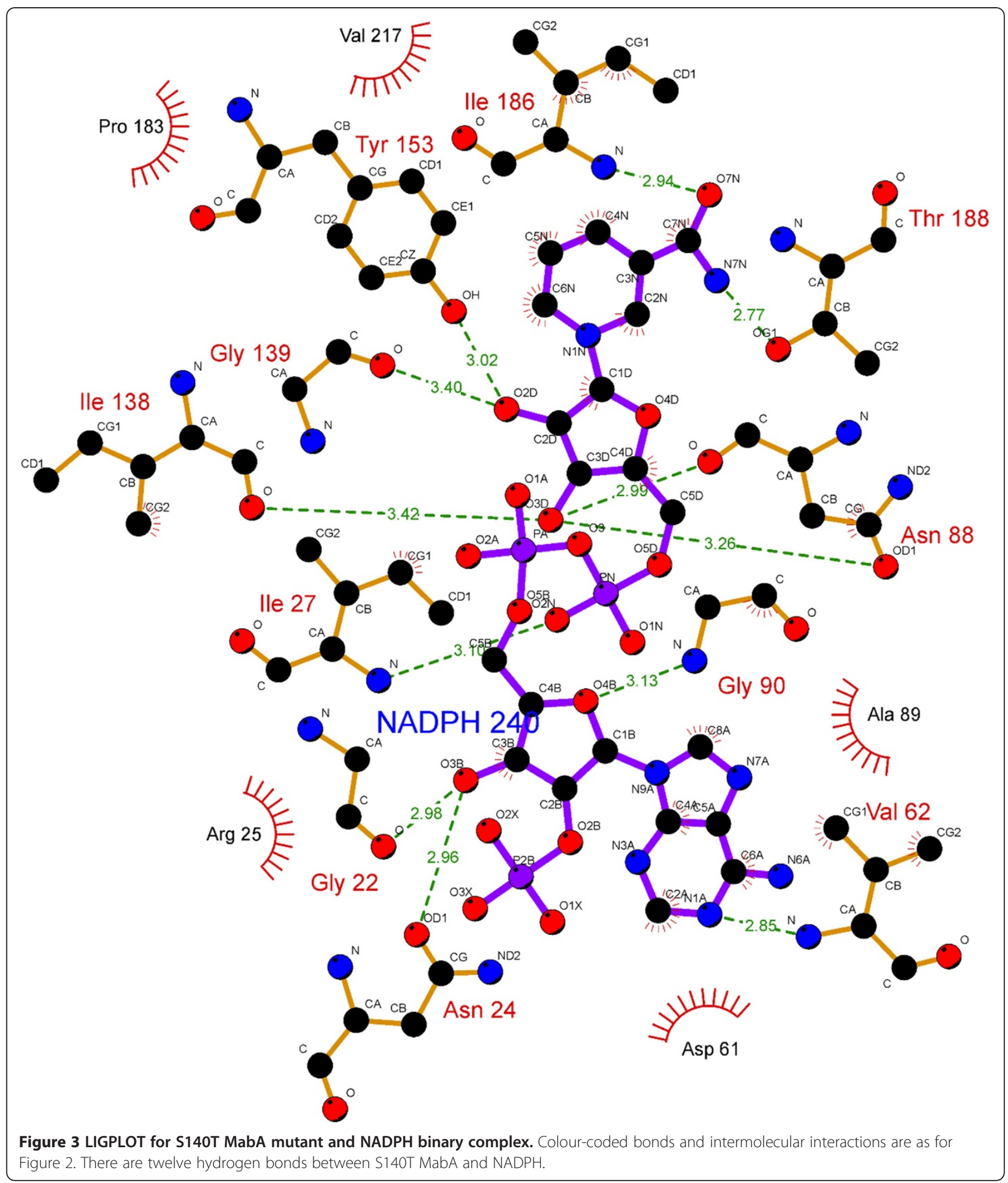

values of $47 \mu \mathrm{M}$ for $K$, the mean dissociation constant for NADPH:WT MabA binary complex formation, and 2 for $h$, the Hill coefficient [20]. This Hill coefficient value is the upper limit for dimeric proteins, indicating complete positive cooperativity. An assumption of all-or-none (as in the symmetry model) is implicit in the Hill equation [36]. Accordingly, in the simplest case of strong positive homotropic cooperativity, an estimate for the intrinsic dissociation constant of NADPH binding to WT MabA (considering $K=K_{1} K_{2}$ ) would have a value of $6.86 \mu \mathrm{M}$. The predicted 


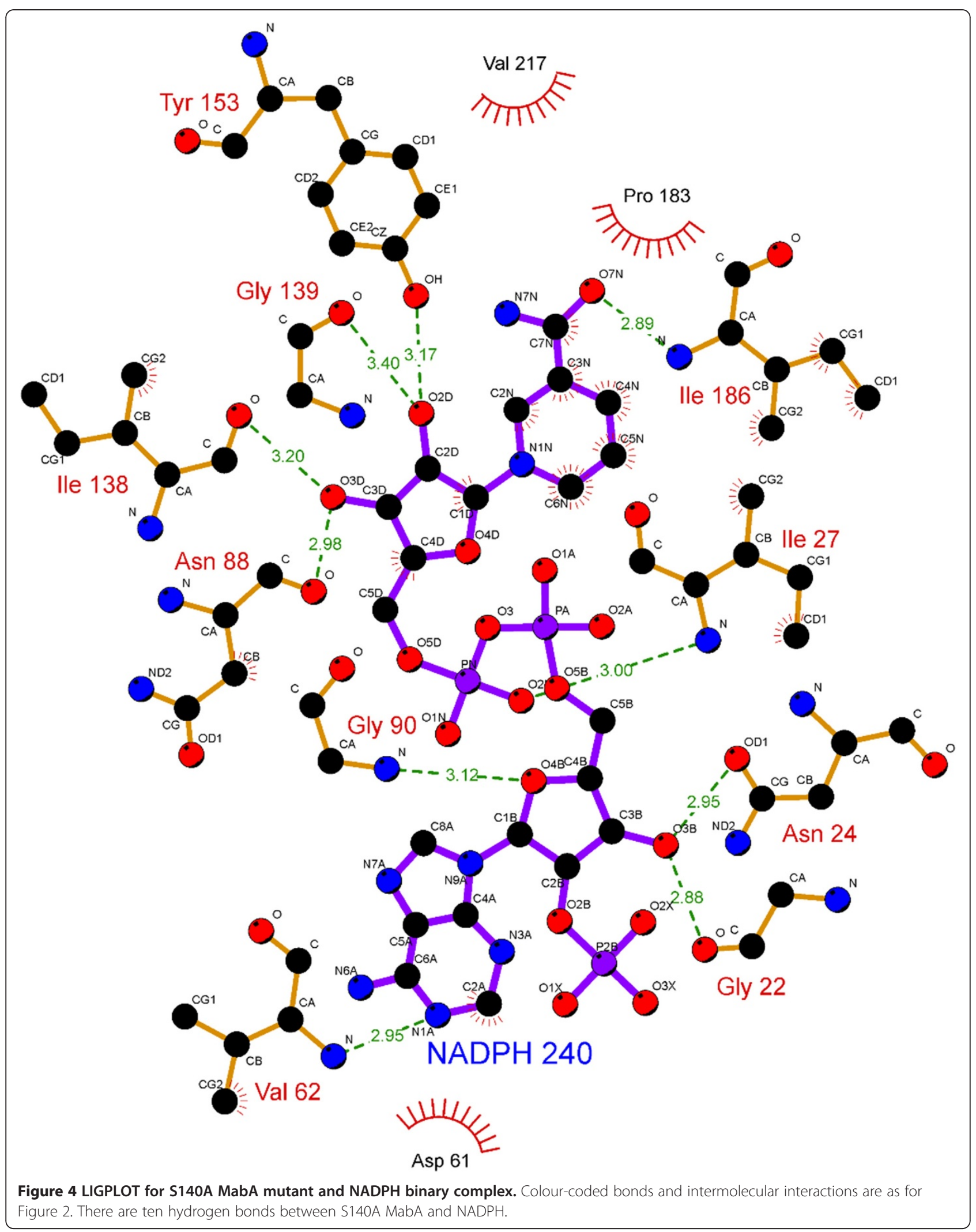




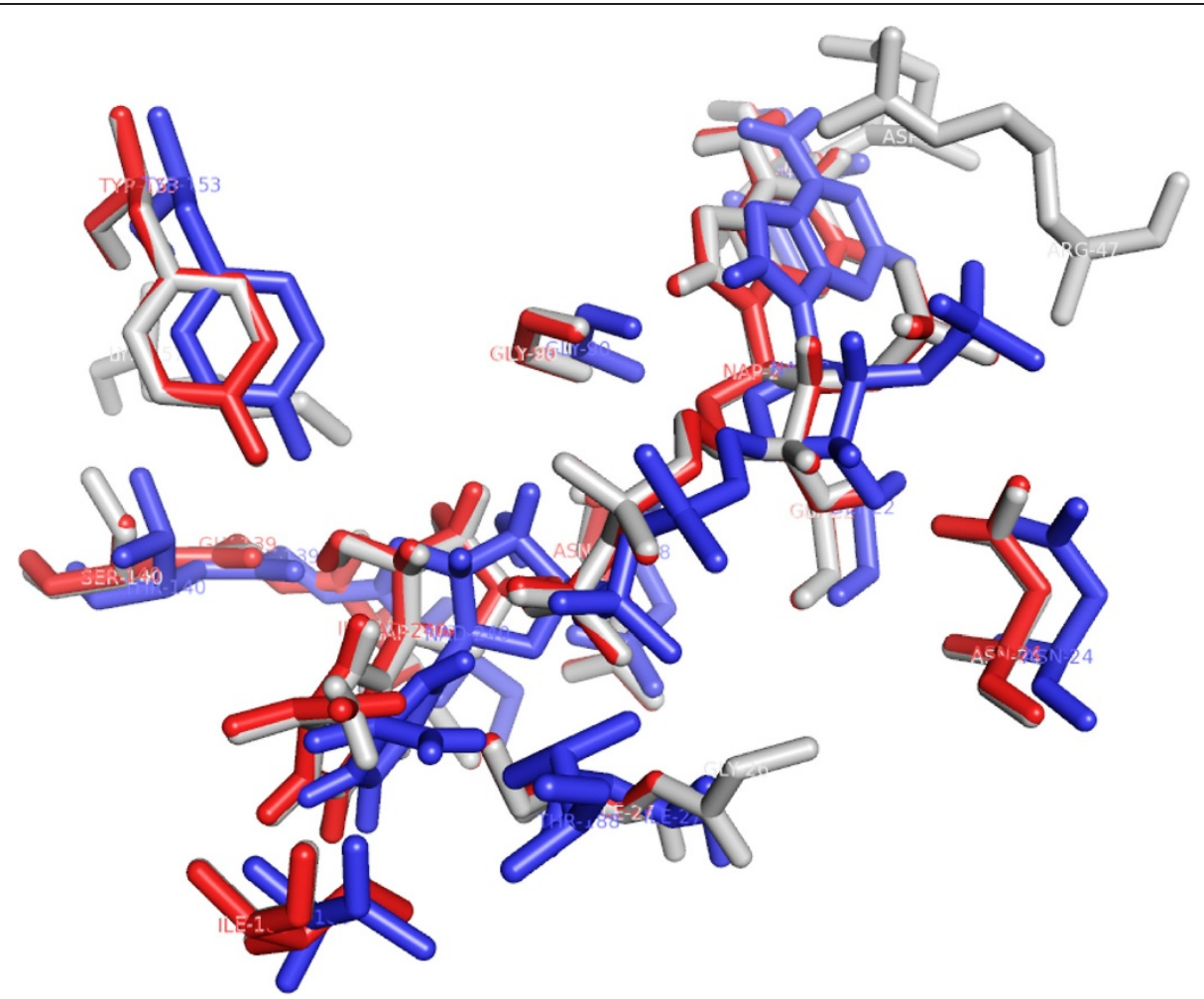

Figure 5 The NADPH binding sites of WT MabA, S140A and S140T models are shown superimposed. The structures are represented in stick model. WT MabA (light gray), S140A (red), and S140T (blue).

$\mathrm{p} K_{\mathrm{d}}$ values are in good agreement with fluorescence spectroscopy data, showing that larger $\mathrm{p} K_{\mathrm{d}}$ values correspond to lower dissociation constant values for binary complex formation. It should be pointed out that even though the $\mathrm{p} K_{\mathrm{d}}$ values estimated by the XSCORE [32], LigScore [33] and Drugstore [34] programs are different, they all show the same trend in overall dissociation constants for binary complex formation (Table 2). In addition, $\mathrm{p} K_{\mathrm{d}}$ values do not give a good prediction of the experimental $K_{\mathrm{d}}$ values.

There have been numerous reports showing that the central acid-base catalyst in SDRs is a Tyr group that donates or abstracts a proton to/from the substrate [16]. To function as a base, tyrosine must be ionized (tyrosinate). However, the normal $\mathrm{p} K_{\mathrm{a}}$ of $\mathrm{Tyr}$ is 10.2 , which would make it difficult to ionize in neutral solutions. In the active site of SDR proteins, the $\mathrm{p} K_{\mathrm{a}}$ of Tyr is lowered by approximately four $\mathrm{pH}$ units by the positive electrostatic field created by a conserved Lys and the quaternary

Table 2 XSCORE, DrugScore and LigScore evaluation upon binary complex formation

\begin{tabular}{llll}
\hline & XSCORE $^{\mathbf{a}}$ & DrugScore & LigScore \\
\hline MabAWT & 7.15 & -139 & $-14,57$ \\
MabAS140A & 7.06 & -136 & $-12,18$ \\
MabAS140T & 6.10 & -119 & $-9,30$ \\
\hline
\end{tabular}

${ }^{\mathrm{a}}$ Given in units of $\mathrm{pK}_{\mathrm{d}}$. nitrogen of oxidized, charged cofactor nicotinamide. The Lys $\epsilon$-amino group is also involved in nicotinamide ribose binding. However, pH-dependence of WT MabA kinetic parameters indicated that a single enzyme group with $\mathrm{p} K_{\mathrm{a}}$ value of 9.6 abolishes activity upon deprotonation [17]. This $\mathrm{p} K_{\mathrm{a}}$ value, as pointed out above, prompted the authors to suggest that either Tyr or Lys of MabA catalytic triad plays a role in catalysis and/or substrate binding. These results underscore the need to present experimental data to support a predicted role to any amino acid residue, since there appears to be no need to lower the $\mathrm{p} K_{\mathrm{a}}$ value of catalytic Tyr side chain of MabA. A conserved active site Asn residue and its main chain carbonyl group interacts with a water molecule that is in $\mathrm{H}$ bonding distance to the active site Lys, thereby establishing a proton relay system connecting bulk solvent to the active site Tyr residue in SDR proteins [37]. Site-directed mutagenesis of Ser138 residue of the Gram-negative bacterium Comamonas testosteroni $3 \beta / 17 \beta$-hydroxysteroid dehydrogenase $(3 \beta / 17 \beta-H S D)$ protein, an SDR family member, has shown that S138A mutation resulted in complete loss of activity, whereas S138T mutant had steady-state kinetic parameters comparable to WT $3 \beta /$ $17 \beta$-HSD enzyme [38]. Based on these results, it was proposed that the hydroxyl group of S138 side chain is essential for catalytic activity, playing a role in stabilization 
and/or polarization of carbonyl substrate and hydrogen bonding to the hydroxyl group of the conserved Tyr [38]. These authors have also pointed out that "it is not clear why in all SDR sequences thus far characterized Thr is conspicuously absent at this position, since our in vitro replacement of Ser138 with Thr yielded an active protein with identical catalytic constants". However, here we show that the MabA S140T mutant has impaired $\mathrm{NADPH}$ binding and no enzyme activity could be detected, suggesting that, contrary to $3 \beta / 17 \beta-H S D$, Thr cannot replace Ser140 in MabA. It is tempting to suggest that impaired NADPH binding of S140T mutant as compared to WT and S140A MabA proteins is due to the bulkier side chain of threonine, which is borne out by the weaker intermolecular contact between NADPH and enzyme binding site (Figure 5). Although the S140A mutant is able to bind NADPH, this mutation results in inactive MabA enzyme. Accordingly, these results point to S140 residue of MabA as a residue whose main role appears to be in catalysis, in agreement with S138 of the catalytic triad of Drosophila alcohol dehydrogenase, also an SDR protein [18]. Notwithstanding, the S140 side chain may also play an indirect role in NADPH binding as the S140T showed impaired dinucleotide binding, in agreement with both the MabA: NADPH (Figures 2, 3, 4 and 5) and MabA:cofactor: substrate molecular models [39]. Interestingly, a conspicuous consequence of replacing S140 with threonine (Figure 3) or alanine (Figure 4) is on Lys157 which is no longer within the $3.5 \AA$ cutoff for hydrogen bonding distance. Accordingly, the S140 residue appears to anchor the Lys157 catalytic triad of MabA. On the other hand, the S140 residue appears to have no effect on the Tyr153 of the catalytic triad of MabA. It has been proposed that a switch from "closed" to "open" conformation of MabA upon NADPH binding brings the phenol ring of catalytic Tyr153 side chain to the active site and that Ser140 induces this rearrangement [38]. However, we have recently shown that there are two forms of MabA in solution that differ in affinity for NADPH [20], which could imply that the "open" and "closed" conformations exist in equilibrium prior to $\mathrm{NADPH}$ binding. Interestingly, although tetrameric $\beta$-ketoacyl Reductase from Escherichia coli [40], Plasmodium falciparum [41] and Brassica napus [42] display negative homotropic cooperativity; $\beta$-ketoacyl Reductase from M. tuberculosis (MabA) [20] and Staphylococcus aureus [43] exhibit positive homotropic cooperativity. Unfortunately, attempts to obtain crystals of S140T and S140A MabA mutants have been unsuccessful in our hands.

\section{Conclusions}

The S140 side chain appears to play a role in MabA catalysis that is likely not lowering the $\mathrm{p} K_{\mathrm{a}}$ value of Tyr153. Interestingly, there was a shift from sigmoidal for WT MabA [20] to hyperbolic for S140A (Figure 1) titration curve upon NADPH binding. This finding suggests that the S140 residue may play a role in displacing the pre-existing equilibrium between two forms of MabA in solution, thereby affecting enzyme activity. Nina M. Goodey and Stephen J. Benkovic have pointed out that chemical compounds that can shift the equilibrium to protein conformers with lower substrate affinity and/or less catalytically competent must also be considered in drug design [44]. Ideally though, the crystal structure of S140A mutant protein should be obtained to shed further light on the role of this residue in MabA.

\section{Abbreviations}

TB: Tuberculosis; MDR-TB: Multi-Drug Resistant TB; XDR-TB: Extensively DrugResistant; FAS: Fatty Acid biosynthesis System; MabA: Mycobacterium tuberculosis $\beta$-ketoacyl-ACP Reductase; SDR: Short-chain Dehydrogenases/ Reductase; $K_{d}$ : Overall dissociation constant; $3 \beta / 17 \beta-H S D$ : Comamonas testosteroni $3 \beta / 17 \beta$-hydroxysteroid dehydrogenase.

\section{Competing interests}

The authors declare that they have no competing interests.

\section{Authors' contributions}

Conceived and designed the experiments: LAR, RAC, WFA, DSS and LAB, Performed the experiments: LAR and RAC. Analyzed the data: LAR, RAC and LAB. Contributed reagents/materials/analysis tools: WFA, LAB and DSS. Wrote the paper: LAR, LAB and DSS. All authors read and approved the final manuscript.

\section{Acknowledgments}

Financial support for this work was provided by Millennium Initiative Program and National Institute of Science and Technology on Tuberculosis, MCT-CNPq, Ministry of Health-Department of Science and Technology (Brazil) to DSS and LAB LAB and DSS also acknowledge financial support awarded by FAPERGS-CNPq-PRONEX-2009. DSS (304051/1975-06), LAB (520182/99-5) and WFAJr (300851/98-7) are research career awardees from the National Council for Scientific and Technological Development of Brazil (CNPq). LAR and RAC were supported by studentships from CNPq.

\section{Author details}

${ }^{1}$ Centro de Pesquisas em Biologia Molecular e Funcional (CPBMF), Instituto Nacional de Ciência e Tecnologia em Tuberculose (INCT-TB), Pontifícia Universidade Católica do Rio Grande do Sul (PUCRS), Av. Ipiranga 6681, Porto Alegre, RS 90619-900, Brazil. ${ }^{2}$ Programa de Pós-Graduação em Medicina e Ciências da Saúde, PUCRS, Av. Ipiranga 6681, Porto AlegreRS 90619-900, Brazil. ${ }^{3}$ Faculdade de Biociências, Laboratório de Bioquímica Estrutural, PUCRS, Av. Ipiranga 6681, Porto Alegre, RS 90619-900, Brazil. ${ }^{4}$ Programa de Pós-Graduação em Biologia Celular e Molecular, PUCRS, Av. Ipiranga 6681 Tecnopuc - Prédio 92A, ZIP CODE 90619-900, Porto Alegre, RS, Brazil.

Received: 7 May 2012 Accepted: 14 September 2012

Published: 25 September 2012

\section{References}

1. Harries AD, Dye C: Tuberculosis. Ann Trop Med Parasitol 2006, 100:415-431.

2. World Health Organization: Global Tuberculosis Control -Epidemiology, Strategy, Financing. www.who.int/tb/publications/global_report/2009.

3. Centers for Disease Control and Prevention (CDC): Emergence of Mycobacterium tuberculosis with extensive resistance to second-line drugs - worldwide, 2004-2006. MMWR Morb Mortal Wkly Rep 2006, 55:301-305.

4. Dorman SE, Chaisson RE: From magic bullets back to the magic mountain: the rise of extensively drug-resistant tuberculosis. Nat Med 2007, 13:295-298.

5. Singh JA, Upshur R, Padayatchi N: XDR-TB in South Africa: no time for denial or complacency. PLoS Med 2007, 4:e50. 
6. Velayati AA, Farnia P, Masjedi MR, Ibrahim TA, Tabarsi P, Haroun RZ, Kuan HO, Ghanavi J, Farnia P, Varahram M: Totally drug-resistant tuberculosis strains: evidence of adaptation at the cellular level. Eur Respir J 2009, 34:1202-1203.

7. Velayati AA, Masjedi MR, Farnia P, Tabarsi P, Ghanavi J, ZiaZarifi AH, Hoffner SE: Emergence of new forms of totally drug-resistant tuberculosis bacilli. Chest 2009, 136:420-425.

8. Banerjee A, Sugantino M, Sacchettini JC, Jacobs WR Jr: The mabA gene from the inhA operon of Mycobacterium tuberculosis encodes a 3-ketoacyl reductase that fails to confer isoniazid resistance. Microbiology 1998, 144:2697-2707.

9. Parish T, Roberts G, Laval F, Schaeffer M, Daffe M, Dunkan K: Functional complementation of the essential gene fabG1 of Mycobacterium tuberculosis by Mycobacterium smegmatis fabG but not Escherichia coli fabG. J Bacteriol 2007, 189:3721-3728.

10. Veyron-Churlet R, Zanella-Cleon I, Cohen-Gonsaud M, Molle V, Kremer L: Phosphorylation of the Mycobacterium tuberculosis $\beta$-ketoacyl-acyl carrier protein reductase MabA regulates mycolic acid biosynthesis. J Biol Chem 2010, 285:12714-12725.

11. Cantaloube S, Veyron-Churlet R, Haddache N, Daffé M, Zerbib D: The Mycobacterium tuberculosis FAS-II dehydratases and methyltransferases define the specificity of the mycolic acid elongation complexes. PLOS One 2011, 6(12):e29564.

12. Robertson JG: Enzymes as a special class of therapeutic target: clinical drugs and modes of action. Curr Opin Struct Biol 2007, 17:674-679.

13. Oppermann U, Filling C, Hult M, Shafqat N, Wu X, Lindh M, Shafqat J, Nordling E, Kallberg Y, Persson B, Jörnval H: Short-chain dehydrogenases/reductases (SDR): the 2002 update. Chem Biol Interact 2003, 143-144:247-253.

14. Marrakchi H, Ducasse S, Labesse G, Montrozier H, Margeat E, Emorine L, Charpentier X, Mamadou D, Quémard A: MabA (FabG1), a Mycobacterium tuberculosis protein involved in the long-chain fatty acid elongation system FAS-II. Microbiology 2002, 148:951-960.

15. Cohen-Gonsaud M, Ducasse S, Hoh F, Zerbib D, Labesse G, Quémard A: Crystal structure of MabA from Mycobacterium tuberculosis, a reductase involved in long-chain fatty acid biosynthesis. J Mol Biol 2002,320:249-261.

16. Kanavagh $\mathrm{KL}$, Jörnvall $\mathrm{H}$, Persson $\mathrm{B}$, Oppermann U: The SDR superfamily: functional and structural diversity within a family of metabolic and regulatory enzymes. Cell Mol Life Sci 2008, 65:3895-3906.

17. Silva RG, Carvalho LP, Blanchard JS, Santos DS, Basso LA: Mycobacterium tuberculosis beta-ketoacyl-acyl carrier protein (ACP) reductase: kinetic and chemical mechanisms. Biochemistry 2006, 45:13064-13073.

18. Winberg J-O, Brendskag MK, Sylte I, Lindstad RI, McKinley-McKee JS: The catalytic triad in Drosophila alcohol dehydrogenase: $\mathrm{pH}$, temperature and molecular modelling studies. J Mol Biol 1999, 294:601-616.

19. Persson $B$, Krook $M$, Jörnvall $H$ : Characteristics of short-chain alcohol dehydrogenases and related enzymes. Eur J Biochem 1991, 200:537-543.

20. Silva RG, Rosado LA, Santos DS, Basso LA: Mycobacterium tuberculosis betaketoacyl-ACP reductase: alpha-secondary kinetic isotope effects and kinetic and equilibrium mechanisms of substrate binding. Arch Biochem Biophys 2008, 471:1-10.

21. Laemmli UK: Cleavage of structural proteins during the assembly of the head of bacteriophage T4. Nature 1970, 227:680-685.

22. Bradford MM, MCRorie RA, Williams WL: A rapid and sensitive method for the quantification of microgram quantities of protein utilizing the principle of protein-dye binding. Anal Biochem 1976, 72:248-254.

23. Kroemer RT, Doughty SW, Robinson AJ, Richards WG: Prediction of the three-dimensional structure of human interleukin-7 by homology modeling. Protein Eng 1996, 9:493-498.

24. Sali A, Blundell TL: Comparative protein modelling by satisfaction of spatial restraints. J Mol Biol 1993, 234:779-815.

25. van Der Spoel D, Lindahl E, Hess B, Groenhof G, Mark AE, Berendsen HJ: GROMACS: fast, flexible, and free. J Comp Chem 2005, 26:1701-1718.

26. Ooestenbrik C, Soares TA, van der Vegt NF, van Gunsteren WF: Validation of the 53A6 GROMOS force field. Eur Biophys J 2005, 34:273-284.

27. Berendsen HJC, Postma JPM, van Gunsteren WF, Hermans J: Interaction models for water in relation to protein hydration. In Intermolecular Forces. Edited by Pullman B. Dordrecht: Reidel D. Publishing Company; 1981:331-342.

28. Laskowski RA, Macarthur MW, Moss DS, Thornton JM: PROCHECK: a program to check the stereochemical quality of protein structures. J App/ Cryst 1993, 26:283-291.
29. Azevedo WF Jr, Mueller-Dieckmann JH, Schulze-Gahmen U, Worland PJ, Sausville E, Kim SH: Structural basis for specificity and potency of a flavonoid inhibitor of human CDK2, a cell cycle kinase. Proc Natl Acad Sci USA 1996, 93:2735-2740.

30. Azevedo WF Jr, Canduri F, Fadel V, Teodoro LG, Hial V, Gomes RA: Molecular model for the binary complex of uropepsin and pepstatin. Biochem Biophys Res Commun 2001, 287:277-281.

31. Wallace AC, Laskowski RA, Thornton JM: LIGPLOT: a program generate schematic diagrams of protein-ligand interactions. Protein Eng 1995, 8:127-134.

32. Wang R, Lai L, Wang S: Further development and validation of empirical scoring functions for structure-based binding affinity prediction. $J$ ComputAided Molecular Des 2002, 16:11-26.

33. Fan H, Schneidman-Duhovny D, Irwin J, Dong GQ, Shoichet B, Sali A: Statistical Potential for Modeling and Ranking of Protein-Ligand Interactions. J Chem Inf Model 2011, 51:3078-3092.

34. Velec HF, Gohlke H, Klebe G: DrugScore(CSD)-knowledge-based scoring function derived from small molecule crystal data with superior recognition rate of near-native ligand poses and better affinity prediction. J Med Chem 2005, 48:6296-6303

35. Monod J, Wyman J, Changeux J-P: On the nature of allosteric transitions: a plausible model. J Mol Biol 1965, 12:88-118.

36. Hill AV: The combinations of haemoglobin with oxygen and with carbon monoxide. Biochem J 1913, 7:471-480.

37. Filling C, Berndt KD, Benach J, Knapp S, Prozorovski T, Nordling E, Ladenstein R, Jörnvall H, Oppermann U: Critical residues for structure and catalysis in short-chain dehydrogenases/reductases. J Biol Chem 2002, 277:25677-25684.

38. Oppermann UCT, Filling C, Berndt KD, Persson B, Benach J, Ladenstein R, Jörnvall $\mathrm{H}$ : Active site directed mutagenesis of $3 \beta / 17 \beta$-hydroxysteroid dehydrogenase establishes differential effects on short-chain dehydrogenase/reductase reactions. Biochemistry 1997, 36:34-40.

39. Cohen-Gonsaud M, Ducasse-Cabanot S, Quémard A, Labesse G Ligand-induced fit in mycobacterial MabA: the sequence-specific Cterminus locks the conformational change. Proteins 2005, 60:392-400.

40. Price AC, Zhang YM, Rock CO, White SW: Structure of beta-ketoacyl-[acyl carrier protein] reductase from Escherichia coli: negative cooperativity and its structural basis. Biochemistry 2001, 40:12772-12781.

41. Karmodiya K, Surolia N: Analyses of co-operative transitions in Plasmodium falciparum beta-ketoacyl acyl carrier protein reductase upon co-factor and acyl carrier protein binding. FEBS J 2006, 273:4093-4103.

42. Sheldon PS, Kekwick RG, Smith CG, Sidebottom C, Slabas AR: 3-Oxoacyl$[\mathrm{ACP}]$ reductase from oilseed rape (Brassica napus). Biochim Biophys Acta 1992, 1120:151-159.

43. Dutta D, Bhattacharyya S, Das AK: Crystal structure and fluorescence studies reveal the role of helical dimeric interface of Stapylococcal FabG1 in positive cooperativity for NADPH. Proteins 2012, 8:1250-1257.

44. Goodey NM, Benkovic SJ: Allosteric regulation and catalysis emerge via a common route. Nat Chem Biol 2008, 4:474-482.

\section{doi:10.1186/1756-0500-5-526}

Cite this article as: Rosado et al.: Role of Serine140 in the mode of action of Mycobacterium tuberculosis $\beta$-ketoacyl-ACP Reductase (MabA). BMC Research Notes 2012 5:526.

\section{Submit your next manuscript to BioMed Central and take full advantage of:}

- Convenient online submission

- Thorough peer review

- No space constraints or color figure charges

- Immediate publication on acceptance

- Inclusion in PubMed, CAS, Scopus and Google Scholar

- Research which is freely available for redistribution 